\title{
O empresariado industrial e a educação brasileira
}

\author{
Ramon de Oliveira
}

Universidade Federal de Pernambuco, Centro de Educação

\section{Introdução}

De acordo com o empresariado industrial brasileiro, o combate à pobreza no Brasil depende do desenvolvimento de medidas que permitam às indústrias nacionais competirem, em igualdade de condições, com as estrangeiras. Nesse sentido, além da necessária diminuição dos custos da produção, o empresariado advoga a reestruturação do sistema educacional brasileiro, as quais, na sua compreensão, são condições indispensáveis para o crescimento industrial produzir também o aumento da oferta de empregos.

As posições assumidas pelo empresariado industrial brasileiro são muito parecidas com as do Banco Mundial, tendo em vista o fato de esta instituição considerar que o caminho para a nação brasileira é o aumento da sua competitividade econômica e as reformas econômica e política. Defensor da reestruturação do Estado e da redução de suas intervenções nas áreas sociais - como saúde, educação e alimentação -, o empresariado advoga o envolvimento dos setores econômicos e políticos nesse processo.
Essas considerações deixam claro que a compreensão das políticas educacionais implementadas nos últimos anos pelo governo brasileiro requer a análise de como o empresariado tem interferido na confecção dessas políticas. Este artigo busca contribuir nesse sentido. Dialogando com as proposições educacionais do empresariado industrial tornadas públicas no transcorrer da década de 1990, procurarei demonstrar que há uma relativa sintonia entre as propostas desse empresariado e o conjunto de reformas e políticas educacionais, implementadas pelo governo Fernando Henrique Cardoso no transcorrer dos seus dois mandatos consecutivos.

\section{0 empresariado e a educação}

Preocupado com a articulação entre competitividade industrial e formação de capital humano, em 1988, no documento Competitividade industrial (Confederação Nacional da Indústria - CNI -, 1988), o empresariado desenvolveu um conjunto de críticas ao sistema educacional brasileiro, apontando que sua fragilidade contribuía para o constrangimento da forma- 
ção de mão-de-obra qualificada para atender às novas demandas existentes no mercado de trabalho. Embora direcionadas à educação básica, suas críticas privilegiaram o ensino superior, como podemos observar a seguir:

1) Maior rigor na transferência de recursos para o sistema universitário.

2) Incentivos à participação de recursos privados na manutenção do sistema de ensino público;

3) Apoio à educação básica.

4) Melhores condições para a integração dos docentes em atividades fora da universidade. (p. 20)

Entendo que enquanto a primeira proposta se refere à produtividade e à eficiência, que valorizam os mecanismos de avaliação há muito estabelecidos nos cursos de pós-graduação, a segunda demonstra o interesse do empresariado em intervir na gestão do sistema público de ensino. $\mathrm{O}$ empresariado não apenas se apresenta como possível sócio no financiamento da educação pública, mas advoga para si a possibilidade de interferir na direção dada ao seu financiamento. Já a quarta proposta demonstra seu interesse em beneficiar-se da estrutura já existente nas instituições públicas de ensino superior: propõe que, mesmo os profissionais mantendo o tempo integral nas universidades públicas, possam prestar serviços à iniciativa privada.

Deve-se considerar que, embora esse discurso do empresariado industrial direcione sua atenção à educação básica, isso não significa que, em plano mais geral, esteja construindo estratégias que contribuam ou pressionem o Estado a direcionar mais recursos para tal segmento da política educacional brasileira.

Efetivamente, há de se investigar, em uma amplitude bem maior do discurso, o quanto um sujeito político tem real interesse em construir uma nova institucionalidade da educação. Nesse sentido, pode-se observar que o empresariado não estabelece práticas concretas visando à constituição de um modelo econômico e social includente. Assim, é de se questionar o quanto tem interesse em modificar a situação da educação básica.
Talvez a forma mais correta de entender e problematizar os limites do pensamento empresarial para a educação seja conhecer qual o verdadeiro fim ou objetivo maior que busca realizar em cada momento histórico. Nesse sentido, não falo de um objetivo específico, que seja exclusivamente seu e que possa se realizar independentemente da ação de outras forças sociais, no interior da sociedade; falo de um projeto social e econômico que possa se estabelecer enquanto hegemônico, subordinando, inclusive, os interesses das classes adversárias.

Esta discussão torna-se mais evidente quando se leva em consideração a análise desenvolvida por Rodrigues (1998), destacando o pensamento pedagógico da CNI e afirmando que a eleição, pelo empresariado, da educação como uma das prioridades nacionais é expressão de uma metamorfose dos objetivos desse sujeito econômico e político. Para o autor, podese visualizar que, desde sua formação, a CNI vem modificando seus objetivos e, à medida que essas alterações acontecem, reelabora seu discurso e modifica suas práticas de forma que alcance a hegemonia necessária para a concretização de seus interesses.

Para Rodrigues, a partir da década de 1980 o télos da CNI é a concretização de uma economia competitiva. Este, como outros télos perseguidos por essa instituição ao longo dos anos (nação industrializada, país desenvolvido), tem fundamentalmente caráter econômico, o que provoca que outros conceitos subordinados a esse télos também passem a ter o mesmo caráter.

A educação, efetivamente, estaria inserida no conjunto de conceitos subordinados a esse novo télos, e talvez seja exatamente aí que podemos justificar a nossa afirmação anterior, de que é necessário ir além do discurso de valorização da educação básica para se compreender o que de fato o empresariado está objetivando com o processo educativo. A educação, assim como as outras políticas sociais, passa a ser pensada dentro da lógica de custo/benefício e de contribuição para o novo projeto político e social que a burguesia industrial busca consolidar. Dessa forma, a valorização da educação básica não implica em maiores investimentos, 
mas em obter melhores resultados, se possível até com menores investimentos (Gentili, 1998).

No documento do Instituto Herbert Levy Ensino fundamental e competitividade empresarial (IHL, 1992), direcionando sua atenção ao ensino fundamental, seus formuladores destacaram duas problemáticas como as mais expressivas. A primeira diz respeito ao financiamento e a segunda, à qualidade.

Sobre o financiamento, destaca que, tanto em sua concepção quanto em sua implementação, há distorções que impedem um melhor rendimento por parte desse nível de ensino. Afirma que, além do Estado não cumprir o estabelecido na Constituição Federal no que diz respeito ao financiamento, também há incompetência ou ineficiência da burocracia estatal na aplicação dos recursos. Dessa forma, a primeira providência a ser tomada é maior eficiência da máquina administrativa no controle e aplicação dos recursos disponíveis.

Essa posição do empresariado, apontando a ineficiência estatal e a burocratização existente na gestão educacional, faz lembrar o trabalho de Gentili (1998) quando destaca que, no campo educacional, estabelece-se um verdadeiro "Consenso de Washington". Para esse autor, a ofensiva neoliberal no campo educacional, articulada ao conjunto de reformas estruturais implementadas em boa parte da América Latina, forja um novo senso comum tecnocrático que abre muito pouco espaço para se pensar a crise educacional dos países desse continente fora da lógica economicista e privatista.

Conforme a crítica neoliberal, a crise educacional decorre fundamentalmente da incapacidade do Estado articular a progressiva universalização do atendimento educacional, ocorrido nesses últimos anos, com a manutenção/aumento da sua qualidade. Nesse sentido, o problema fundamental da educação estaria no campo do gerenciamento. Essas críticas, segundo Gentili, podem ser entendidas como contestação ao papel interventor do Estado, que, segundo os neoliberais, teria como características a centralização e a burocratização, as quais interferem diretamente na produtividade e na eficiência de seus serviços.
Para Gentili (1998), a crítica neoliberal ao modelo educacional latino-americano - que, a meu ver, está em sintonia com a crítica que os empresários fazem à educação brasileira - pode ser assim sintetizada:

Existe uma crise de qualidade porque os sistemas educacionais latino-americanos não se configuraram como verdadeiros mercados escolares regulados por uma lógica interinstitucional, flexível e meritocrática. A escola está em crise porque nela não se institucionalizaram os critérios competitivos que garantem uma distribuição diferencial do serviço, que se fundamente no mérito e no esforço individual dos "usuários" do sistema. No seu âmbito, não foi estabelecido o necessário sistema de prêmios e castigos, que recompensa ou pune as ações e decisões individuais; em suma, um sistema em que os "melhores" triunfam e os "piores" fracassam. (p. 18)

Dentro dessa lógica, como demonstra Rodrigues (1998), a questão a ser perseguida para solucionar a problemática educacional não estaria no aumento dos investimentos na educação, mas basicamente em como "gastar melhor". Em síntese, o centro da questão estaria em construir nova racionalidade na gestão educacional, daí o fato de os governantes neoliberais buscarem reestruturar a administração educacional.

Ainda segundo o documento do IHL (1992), há diversas expressões da má qualidade do ensino fundamental. Os índices de reprovação, o tempo de permanência dos alunos nas escolas sem alcançarem o grau correspondente a esse tempo de estudo e os maus resultados de aprendizagem são demonstrativos de que o desempenho dos alunos brasileiros é inferior ao dos alunos de outras nações com industrialização recente.

Antes essas constatações, o documento propôs ao governo "atacar" duas questões fundamentais: o estabelecimento de novo modelo de financiamento da escola pública e a implementação de mecanismos de controle da qualidade dessas escolas.

Quanto ao financiamento do ensino fundamental, estipula: 
1) O governo federal estabeleça e torne público um valor anual mínimo de recursos per capita para todos os alunos das escolas de ensino fundamental. (p. 6)

2) O governo federal tome as medidas cabíveis para garantir que todos os alunos do ensino fundamental recebam recursos que lhes forem prometidos, onde quer que estejam matriculados. (p. 8)

Já no que se refere à análise da qualidade da educação, o documento afirma que qualquer empresa, para garantir o controle de qualidade dos seus produtos, necessita estabelecer coerência entre os instrumentos de aferição de qualidade e o produto elaborado. Agindo dessa forma, é possível detectar possíveis falhas e corrigir distorções existentes. Com o processo educativo não seria diferente; basta definir o que o aluno deverá saber ao final de um ciclo de estudos e avaliá-lo para ver se isso acontece.

Entendendo que o controle da qualidade do processo educacional é utilizado em todos os países do Primeiro Mundo, assim como nos países recém-industrializados, e que o Brasil ainda não o havia colocado em prática, propõe o documento:

1) O governo federal implemente diretamente um sistema nacional e permanente de controle de qualidade dos resultados do sistema escolar.

2) O governo federal, em colaboração com o Senac e o Senai, avalie, através de testes padronizados, e de maneira sistemática, o alcance dos objetivos considerados como competências básicas para operar em uma sociedade industrialmente moderna e competitiva. (p. 9)

Como apresentado nas críticas de Gentili (1998), em momento algum os setores ligados ao grande capital visualizam a problemática educacional intimamente vinculada às relações de desigualdade que imperam nos países da América Latina. O empresariado brasileiro não se distancia daqueles que entendem que as soluções para a educação podem e devem ser encontradas no interior do sistema educacional ou na restruturação administrativa do Estado.

Se essa elite procurasse entender a problemática educacional em maior amplitude perceberia que existem limites sociais, criados e reforçados por ela própria, que definem a impossibilidade de um contigente maior da população ter acesso a uma escola de melhor qualidade. Em outras palavras, há determinações sociais que impedem que um contingente considerável da população ingresse e permaneça com sucesso no sistema educacional. Por outro lado, esse próprio sistema mostra deficiências crônicas e mesmo aqueles que nele permanecem não conseguem alcançar um nível de formação que seja considerado satisfatório para um cidadão, nos dias atuais. Como diz Gentili (1994):

\footnotetext{
Não existe "qualidade" com dualização social. Não existe "qualidade" possível quando se discrimina, quando as maiorias são submetidas à miséria e condenadas à marginalidade, quando se nega o direito à cidadania a mais de dois terços da população [...]. [Não podemos aceitar] uma sociedade onde o discurso da qualidade como retórica conservadora seja apenas uma lembrança deplorável da barbárie que significa negar às maiorias seus direitos. (p. 177)
}

Quando o empresariado recomenda, para a melhoria da qualidade de ensino, os mesmos mecanismos utilizados no processo de produção, torna clara a ótica economicista e fragmentária que norteia suas proposições educacionais. Por outro lado, como destaca Gentili (1994), encontrar no âmbito do processo de produção saídas para os problemas da educação expressa a quem os neoliberais reservam a capacidade de reverter o mau desempenho do sistema educacional. Ou seja, se os homens de negócios souberam enfrentar os seus desafios, se foram capazes de conseguir êxitos em suas empreitadas, devemos nos inspirar neles para modificar o panorama educacional.

Para os empresários e outros neoliberais, somente através do estabelecimento de uma lógica competitiva e meritocrática no cotidiano escolar poderão ser 
efetuadas mudanças capazes de conquistar uma nova realidade educacional.

Uma complementação a essa análise de Gentili pode ser feita ao considerarmos que o empresariado, à medida que vai mudando seu projeto societário, vai também redefinindo o papel da educação nesse processo. Sendo fundamental criar novas bases para uma sociedade competitiva, o modelo de formação estabelecido, bem como a própria institucionalidade da educação, precisam ser repensados. O que for expressão da continuidade é considerado arcaico e passível de modificação. Ou seja, se temos a crise de um projeto societário e se instaura um novo télos, nada mais correto, como podemos apreender de Rodrigues (1998), que seja atribuída a novos sujeitos a capacidade de solucionar os problemas educacionais, ao mesmo tempo em que se estabelecem novos critérios de valorização do que é uma educação de qualidade.

Entre suas recomendações, o IHL afirma a necessidade de serem destinados maiores investimentos para o ensino fundamental. Quanto a isso, todos estamos plenamente de acordo. Inclusive, esse aumento de recursos não deve restringir-se ao ensino fundamental, mas direcionar-se a toda a educação básica e ao ensino superior. A incoerência das afirmações expressa-se, exatamente, no momento que se coloca a necessidade de diminuição de recursos para o ensino superior. Ora, os formuladores desse documento parecem esquecer que o ensino superior brasileiro está em grande parte sob responsabilidade da iniciativa privada, cabendo ao poder público uma parcela inferior a 30\% (INEP, 1999). A privatização do ensino superior torna-se mais evidente quando observamos que entre os anos de 1994 e 1998 as matrículas na rede federal cresceram apenas $12,4 \%$, enquanto na rede privada esse percentual chegou a mais de $36 \%$ (idem).

No documento Educação básica e formação profissional: a visão dos empresários (CNI, 1993), ${ }^{1}$ o

${ }^{1} \mathrm{O}$ Senai foi um dos elaboradores desse documento. Anoto também que a elaboração final dele ficou a cargo do professor Nassin Mehedff, que posteriormente assumiu a direção da Secre- empresariado destaca a importância da educação como um aspecto importante na formação dos indivíduos para a vivência em sociedade. Contudo, por possuir uma compreensão economicista e fragmentária acerca das múltiplas relações nas quais os indivíduos estão inseridos, termina por valorizar muito mais o papel da escola como espaço de preparação do indivíduo para o mercado de trabalho. Por conseguinte, ainda que se esboce, nesse documento, a defesa da universalização da educação básica, o fundamental para o empresariado era que a educação estivesse a serviço dos interesses imediatos da produção, como pode ser evidenciado na citação a seguir:

O que é necessário defender é um sistema educacional que forme o homem auto-realizado, com uma instrução tão completa e geral que o torne capaz de se recambiar nas diversas tarefas e qualificações que a nova empresa exigirá e, portanto, capaz de se mover no interior da organização social do trabalho; um sistema que tenha uma política de formação para os possíveis "excluídos" da sociedade do trabalho, aqueles que precisam, com urgência, desenvolver habilidades que esta nova situação imporá. (CNI, 1993, p. 8)

Se no âmbito desse documento houve um reducionismo da educação aos interesses imediatos do processo produtivo, em outros momentos, o empresariado procurou afirmar a importância da educação como elemento fundador de uma nova cidadania, para que os indivíduos tenham intervenção mais crítica no interior da sociedade. Entretanto, quando isso ocorreu, o empresariado elegeu a educação como meta fundamental para alavancar a modernização, responsabilizando-a pela mudança na problemática social. Isso pode ser constatado em uma entrevista concedida pelo presidente da Federação das Indústrias do Estado de São Paulo (FIESP):

taria de Formação Profissional (SEFOR), do Ministério do Trabalho. Não é de causar espanto, pois, a proximidade desse documento com o que veio a balizar as ações direcionadoras do PLANFOR, sob a coordenação do mesmo Nassin Mehedff. 
Em primeiro lugar está a educação. Evidentemente, ela cada vez toma mais lugar em tudo que se faz. Sem educação, sem instrução, você não tem trabalhador, não tem dirigente, não tem empresa, não tem políticos, não tem imprensa. Então a educação é a alavanca e o motor de tudo, ainda mais numa época de competição cada vez mais acirrada, de luta por espaço. Enfim a educação realmente é o capital humano, não apenas da indústria, mas de uma nação que queira ser séria. Por ela é que vamos poder eliminar as desigualdades, diminuir a fome, a miséria, vamos poder participar dos benefícios da sociedade, do capitalismo e da democracia. Não adianta ter democracia se o sujeito é um ignorante, um esfomeado que não sabe se vota no $\mathrm{A}$, no $\mathrm{B}$ ou no $\mathrm{C}$, se não é capaz de entender um programa de governo, se não é capaz de entender uma prioridade, por que isto é isto, por que aquilo é aquilo [...]. (Ferreira, 1995, p. 5)

Por mais que o empresariado procure, no discurso, imputar à educação outras responsabilidades que não exclusivamente a formação de capital humano, não consegue desviar-se dela. Por parte dos setores ligados ao capital, a leitura do real se assenta em pressupostos analíticos que não apontam de forma alguma para a necessária ruptura com o modelo social vigente. Para essa parte minoritária da população, as instituições sociais devem direcionar-se para a conservação dos valores e do status quo. A mudança é bem-vinda, desde que esteja atrelada a um projeto maior de conservação dos interesses do capital.

A flexibilização das relações de trabalho, a reestruturação do papel do Estado, a modificação na formação dos trabalhadores e uma nova qualidade da educação básica são expressões de "transformações" que são aceitas pelo capital, desde que consolidem mais ainda seus interesses.

Nesse conjunto de ações que "mudam para conservar", o estatuto da educação continua sempre sendo determinado pelo econômico. Passa o tempo e o capital não consegue ver na educação outra coisa senão um instrumento subordinado ao desempenho econômico dos indivíduos e da sociedade. A teoria do capital humano, ainda que reiteradamente criticada (Frigotto, 1989, 1995; Oliveira, 2001a), não deixa de ser a referência que o empresariado utiliza para promover suas interpretações e sugestões de políticas. Nada mais coerente que essa articulação; afinal, para quem não objetiva mudar radicalmente o real, só teria sentido apoiar-se em uma "teoria" que em nada contribui para pensar a educação sobre outras bases que não seja a de reprodução do modelo capitalista de produção.

\section{0 empresariado e a educação: participar para privatizar}

No documento da CNI (1993), ao apresentar uma proposta de política para a educação, o empresariado não reduziu seu papel ao de mero propositor de reformas; objetivou também tornar-se um sujeito ativo no processo de reformulação da política educacional. Ao destacar a importância de se implementar um processo de desburocratização da política educacional, com a conseqüente descentralização da gestão educacional, o empresariado, nesse documento, advogou sua participação nos conselhos escolares. Reconheceu para si, assim como para outros setores organizados da sociedade, o direito de interferir diretamente na administração e na confecção dos currículos escolares, de forma que o processo educativo pudesse alcançar os objetivos de produtividade e eficiência por ele almejados.

Essa preocupação do empresariado em participar diretamente na administração escolar pode também ser vista como mais uma das formas de se buscar a privatização do sistema educacional. Como destacou Gentili (1998), a privatização da educação não tem que seguir a mesma lógica que ocorreu com o conjunto de empresas estatais, quando o Estado passou para a mão da iniciativa privada a oferta de certos serviços como água, telefonia, energia elétrica, transporte etc.

No processo educacional, a privatização pode ocorrer de várias formas, desde a iniciativa privada ofertar diretamente o serviço, como buscar que os próprios indivíduos financiem os seus estudos. De qualquer forma, qualquer uma dessas modalidades de pri- 
vatização deixa explícita uma diminuição da intervenção estatal no provimento integral desses serviços. Entenda-se bem: provimento integral, o que não implica dizer que o Estado deixe de intervir, visando assegurar ao capital privado maior apropriação de riqueza.

Se para o empresariado as debilidades do sistema educacional podem ser corrigidas pela modificação na forma de condução e gerenciamento da política educacional, nada aponta para que sua intervenção venha a contribuir para tal objetivo. Talvez, além da arrogância da elite empresarial, marca da ofensiva neoliberal, outro fator que justifica essa tomada de posição seja a ofensiva publicitária que o empresariado utiliza nos dias atuais, buscando disseminar a imagem de que está atento e sensível às questões sociais. Procura passar a imagem para a população de que ele está desencadeando medidas, visando auxiliar o poder público a dirimir as injustiças sociais e as distorções que existem, fundamentalmente, no sistema educacional. Daí provém o fato de serem cada vez mais propagadas ações que o colocam como desenvolvendo atividades de apadrinhamento de alguma escola.

Qualquer que seja o motivo encontrado como estimulador da ofensiva empresarial no campo educacional, o mesmo estará imerso no novo padrão civilizatório que as elites econômicas querem e buscam estabelecer. Padrão esse no qual o direito à educação é passível de questionamento, discussão, flexibilização e verificação de seu retorno econômico. Ou seja, o direito à educação não está imune à lógica mercantil. Portanto, a intervenção empresarial no gerenciamento educacional pode e deve ser pensada no âmbito de um movimento global que busca

\footnotetext{
desintegrar culturalmente a possibilidade mesma de existência do direito à educação (como direito social) e de um aparato institucional que tenda a garantir a concretização de tal direito: a escola pública. (Gentili, 1995, p. 230, grifos do autor)
}

Trazendo à discussão as proposições para a educação da Federação das Indústrias do Estado de São Paulo (FIESP), pode-se observar que a mesma, quando tornou pública uma posição mais elaborada so- bre a importância da educação no seu projeto de desenvolvimento econômico, atribuiu-lhe um papel fundamental na qualificação dos trabalhadores. Para a FIESP (1995), o poder público deveria investir em ações de qualificação dos trabalhadores, porque uma maior qualificação atuaria diretamente na diminuição da concentração de riqueza e no crescimento econômico da nação.

Os recursos humanos - a capacidade de iniciativa, a competência profissional, a inventividade, a disciplina e o hábito de agir no presente tendo em vista o futuro - são fatores de produção pelo menos tão importantes para a criação de riqueza quanto qualquer outro tipo de capital. A tendência no mundo moderno é clara no sentido de tornar o "cérebro", cada vez mais, o fator decisivo para o sucesso econômico. (p. 101)

De acordo com esse documento, o Estado deveria desenvolver uma política social séria. Por isso, não poderia deixar de concentrar maiores esforços e recursos em áreas que eram fundamentais para as populações jovens adquirirem competências que assegurem a conquista de nova cidadania. Nesse sentido, maiores investimentos em educação básica e na capacitação profissional dos jovens de famílias de baixa renda deverão ser assumidos como prioritários.

Para a FIESP, em uma economia de mercado as pessoas devem defender seus próprios interesses. Ao Estado não cabe ser paternalista, mas sim assegurar as condições mínimas para que esses setores de baixa renda possam disputar com outros em melhores condições.

A idéia básica é redistribuir não o resultado, o rendimento que cada indivíduo logra obter no mercado pelo seu esforço e talento, mas sim a dotação inicial, isto é, a oportunidade que o indivíduo terá para desenvolver sua competência profissional e econômica. A igualdade de resultado oprime, a igualdade de oportunidade libera. (FIESP, 1995, p. 112, grifos meus)

O trecho grifado dessa citação deixa claro qual o modelo de sociedade defendido pelo empresariado. 
Considerar que através do estímulo à formação profissional o Estado assegurará oportunidades iguais para indivíduos de classes sociais diferentes é procurar ocultar os motivos pelos quais a própria sociedade apresenta fragmentações tão profundas.

A desigual apropriação da riqueza em uma sociedade marcada pelas relações capitalistas não decorre das diferentes aptidões individuais; é a condição de sobrevivência e reprodução do próprio sistema. É impossível pensar a igualdade de oportunidades, como também de apropriação da produção material e cultural, quando a própria base sobre a qual se sustenta a produção capitalista requer a existência de grupos e indivíduos em condições diferenciadas em relação à propriedade dos meios de produção.

Utilizar o mérito individual como explicação das diferenças sociais, ao mesmo tempo em que se busca legitimar o sistema capitalista - retirando dele a responsabilidade pelas desigualdades existentes -, é o mesmo argumento neoliberal que advoga ser o mercado o espaço próprio para a realização individual. Ou seja, para o neoliberalismo, os indivíduos, com base em seus méritos e em sua racionalidade, são os responsáveis pela prórpia realização pessoal.

No entanto, como destacou Silva (1994), essa racionalidade empreendedora, capaz de se colocar acima das contradições sociais, é mera especulação liberal, desprovida de um mínimo de sustentação teórica e prática. No campo educacional essa posição é muito mais inconseqüente, na medida em que termina por legitimar o processo de desconstrução dos direitos sociais alavancado pela ofensiva neoliberal.

[...] esse consumidor racional e individualista do pensamento liberal é apenas uma ficção na exata medida em que sua suposta soberania está limitada e restringida pelas contingências de seu posicionamento na estrutura econômica e social. Novamente, supor que haja a possibilidade de uma escolha racional e livre é apenas diminuir as chances daqueles que estão mal posicionados para fazer uma escolha racional e livre, enquanto os mais bem posicionados continuarão a fazer escolhas mais "racionais" e "livres". Em ambos os casos, o que se estará produzindo é mais desi- gualdade e assimetria. É até possível que se aumente assim a produtividade e a eficiência, mas é ainda preciso perguntar a quem essa produtividade e eficiência, mais uma vez, estarão servindo. (Silva, 1994, p. 24)

A visão fragmentada dos fatores determinantes dos níveis de pobreza existentes faz com que as elites empresariais, através de seus documentos, atribuam à educação a responsabilidade de sanar a problemática social. Ocultam, no entanto, que, de fato, o modelo econômico determinado pelas elites econômicas, como propugnado no documento da FIESP, define diretamente os índices de concentração de riqueza.

Tanto é verdade o descompromisso do empresariado com a mudança radical da realidade social que quando ele defende maior ação estatal em algumas áreas sociais, como é o caso da educação, sua recomendação vem acompanhada de outra mais coerente com as suas posições: a de que o Estado não precisa, para isso, aumentar os investimentos nessa área.

A matemática de maiores investimentos na formação de capital humano sem o desembolso de mais de recursos só se garantiria, evidentemente, a partir de uma mudança nos modos de financiamento efetuados pelo Estado. Coerentemente, os empresários retomaram a crítica ao governo no que se refere aos investimentos no ensino superior. Segundo o documento da FIESP (1995), em virtude de serem os alunos dos setores economicamente privilegiados os que ocupam as vagas nas universidades públicas, o Estado brasileiro reforça as desigualdades sociais, financiando quem pode pagar pela continuidade dos estudos.

Para evitar tal distorção, recomenda-se a privatização do ensino superior e o estabelecimento de mecanismos compensatórios para assegurar aos alunos mais carentes a possibilidade de cursarem a universidade. Assim, para a FIESP, as bolsas de estudo e/ou o crédito educativo são os mecanismos mais corretos para criação da eqüidade entre os setores economicamente diferenciados.

Para justificar essa posição, vale a pena conside- 
rar quem o empresariado inclui no leque de prioridades do Estado brasileiro:

A tarefa primordial da intervenção do Estado na área social deve ser proteger os interesses permanentes dessa população altamente vulnerável, constituída por crianças e adolescentes que vivem em famílias de baixa renda. É esse o grupo que - mais do que qualquer outro e dentro de um critério de eqüidade e eficiência - deveria representar o alvo privilegiado dos gastos sociais do governo em todos os níveis e do esforço da sociedade para promover a formação de capital humano. (FIESP, 1995, p. 211)

Essa citação evidencia o limite que o empresariado coloca para as ações estatais. Selecionando a faixa da população para a qual o poder público deve direcionar suas atenções e utilizando o expediente de criar uma cisão entre setores distintos da sociedade, procura legitimar o "discurso da necessidade". Encoberto por uma postura de questionamento do raio de ação da intervenção estatal, busca criar um senso comum no qual o Estado apresenta-se como ineficiente por não ter desenvolvido uma política mais seletiva.

Nessa interpretação empresarial, os privilegiados não têm sua existência explicada a partir de uma materialidade. São elementos soltos no ar, exploradores das benesses estatais. Dessa forma, bastaria racionalizar as ações estatais para que fosse garantido aos efetivamente necessitados o usufruto de seu trabalho. Note-se: o Estado no campo social não tem por função ser um sujeito interventor; seu papel deve se reduzir a mero agente caritativo ou assistencialista.

Buscar que o Estado seja mais seletivo em sua intervenção na área social é de fato buscar jogar para o âmbito do mercado o acesso a tais direitos. Tal discussão nos faz lembrar Boron (1999), quando destaca que a política neoliberal, ainda que faça um discurso de maior democracia, na prática impulsiona um modelo social que se caracteriza pela exclusão social. Segundo esse autor, a verdadeira democracia tem como objetivo maior integração social; afinal, em um regime democrático o governo deve voltarse para os interesses do povo. Nesse sentido, implementar ações de cunho assistencialista por parte do Estado só tenderia a reforçar ainda mais a frágil democracia brasileira. Não é focalizando a ação estatal que se estabelecerá a diminuição da desigualdade social; muito menos é pela redução dessa intervenção em áreas passíveis de privatização, como o ensino superior, que aparecerão os recursos para minorar a exclusão social.

A pobreza na sociedade brasileira não pode ser explicada pela má interferência estatal na condução econômica ou pela intervenção equivocada em áreas que poderiam ser melhor trabalhadas se estivessem sob a responsabilidade da iniciativa privada. Se nos prendermos a explicações incapazes de visualizar a problemática social em uma dimensão mais ampla, terminaremos por aceitar verdades que as classes dominantes procuram naturalizar, criando um verdadeiro consenso social. Ou seja, deixaremos de perceber que quando o neoliberalismo se depara com um resultado negativo, decorrente de seu receituário, não reconhece sistematicamente sua responsabilidade por tal fato, mas sempre imputa o fracasso dos seus programas de ajustes à ausência efetiva de uma economia de mercado, além da contínua onipresença do Estado (Salama, 1995).

O Consenso de Washington afirmou que as raízes dos problemas dos países latino-americanos estavam na estratégia de desenvolvimento por eles adotada após a Segunda Guerra Mundial (Portella Filho, 1994). Essa é uma das explicações que buscam naturalizar a crise societária e, ao mesmo tempo, criar as condições ideais no campo do consenso político que assegurem a implementação de reformas estruturais, basicamente marcadas pela diminuição da intervenção estatal no campo social. E é exatamente uma das contradições do projeto neoliberal que merece ser questionada e confrontada pelas forças democráticas. A ofensiva neoliberal radicaliza no seu discurso a afirmação de que o Estado mostrou-se incompetente para conduzir a economia e os serviços sociais, requerendo para tanto a diminuição da sua intervenção. A realidade tem demonstrado, no entanto, que para o neoliberalismo se concretizar enquanto projeto civilizató- 
rio o Estado tem que se mostrar mais forte do que nunca; caso contrário, todo o processo implementado pode ser colocado em perigo.

Um regime democrático, que graças a políticas de "ajuste selvagem" empobrece a cada ano a um número cada vez maior de cidadãos, ou que transforma em letra morta a separação de poderes, ou que neutraliza por completo os débeis impulsos participativos desde a base, pode terminar cavando sua própria sepultura. Um regime, finalmente, que cancela a "cidadania política" conseguida pela reinstauração da democracia com a "descidadanização econômica e social" provocada pelo apogeu do neoliberalismo pode projetar uma superficial impressão de estabilidade, até que de repente se produz a débacle. A progressiva deslegitimação das novas democracias, produto de sua incapacidade para melhorar a sorte das grandes maiorias, dificilmente pode ser considerada um elemento positivo em sua estabilização. (Boron, 1995, p. 85)

Não há como implementar um conjunto de medidas, principalmente as ligadas à diminuição do atendimento social, sem encontrar ações de contestação por parte da sociedade; somente com um Estado forte esse projeto pode tomar vida. Aliás, mais que um Estado forte, estarão se construindo as condições para a concretização de um modelo societário no qual a divergência ao projeto hegemônico passa a ser entendida como uma ação desestabilizante ao sistema social e, portanto, passível de ser reprimida. Assim, não é de causar espanto que os governos nacionais na América Latina tendam a reprimir cada vez mais as ações de contestação a seus programas de ajustes econômicos. Muito menos é de se espantar a subsunção que os Poderes Judiciário e Legislativo vêm apresentando em relação ao Poder Executivo.

\section{0 ensino superior $x 0$ setor produtivo: subordinação a caminho}

No ano de 1998, a CNI lançou o documento Competitividade e crescimento: a agenda da indústria (CNI, 1998), pelo qual recomendou para o ensino superior as seguintes mudanças: a) estimular a integração da universidade-empresa, vinculando o público ao privado;

b) estabelecer critério da competição para a distribuição das verbas entre os centros de ensino e pesquisas e institutos tecnológicos;

c) buscar a aproximação dos centros educacionais às necessidades do mercado;

d) implementar a fiscalização $a$ posteriori das pesquisas universitárias. (p. 81)

Com esses objetivos, em definitivo, buscava-se submeter a estrutura das universidades aos interesses do setor produtivo, indo muito além do documento produzido no final da década de 1980 (CNI, 1988). Dessa vez, de forma mais incisiva, o empresariado não apenas defendeu maior rigor na transferência de recursos para as universidades, mas também propôs que os mesmos fossem transferidos em função da contribuição que as universidades dessem às empresas.

É imperativo o direcionamento da maioria dos recursos destinados à ciência e tecnologia para aqueles projetos com maior afinidade com o setor produtivo. Isto é, projetos que busquem solucionar problemas reais do setor produtivo e que por isso serão rapidamente difundidos, contribuindo efetivamente para o aumento da produtividade da economia e, conseqüentemente, para o crescimento econômico e para a competitividade dos produtos domésticos. (CNI, 1998, p. 80)

Como se já não representasse um atraso para os ideais de universidade pública e gratuita - envolvendo o ensino, a pesquisa e a extensão como atividades indissociáveis -, o empresariado também advogou que fossem revistos os estatutos das universidades públicas brasileiras. Sugeriu que as mesmas adotassem um modelo de gestão semelhante ao da iniciativa privada e que passassem a ter maior flexibilidade administrativa, não apenas para buscar recursos no mercado, mas também para financiar suas próprias políticas de pessoal.

Além desta "autonomia", propôs que as universidades fossem financiadas segundo sua vocação. $\mathrm{Ou}$ seja, o ensino e a pesquisa seriam tratados dissociadamente e, pelo seu perfil, cada universidade deveria 
ter um financiamento diferente. Em minha opinião, aquelas que não contemplassem as atividades ligadas ao que o empresariado compreende como sendo da área de ciência e tecnologia dificilmente teriam condições de manter-se com financiamento do Estado. Mas mesmo aquelas que se encontrassem nessa área teriam que ter o perfil de centros de excelência para serem merecedoras do financiamento estatal.

Defendendo a continuidade dos mecanismos de avaliação das instituições de ensino superior, como o "provão", o empresariado advoga que a qualidade do ensino superior pode ser facilmente constatada por empregadores. Essa posição de subordinar o ensino superior aos seus interesses é plenamente coerente com o movimento que as elites vêm estabelecendo no campo educacional. Como já foi demonstrado em trabalhos anteriores que analisam a influência que as agências internacionais têm na política educacional brasileira (Tommasi et al., 1996, Oliveira, 2001b, entre outros), torna-se cada vez mais evidente que a educação é considerada pelos economistas e políticos como um insumo no processo de produção de mercadorias. Nesse sentido, as ações do Estado no campo educacional são sempre analisadas a partir da relação custo/benefício. No ensino superior, essa situação ainda é mais complexa, na medida em que o grande capital internacional não vislumbra a necessidade de os países em desenvolvimento fortalecerem seus sistemas de ensino superior, nem entendem como necessário o fortalecimento de seu quadro de pessoal no campo da pesquisa.

Deve-se destacar que, além da política de privatização do ensino superior, caracterizada pelo aumento da participação da iniciativa privada na oferta desse nível de ensino, observamos também, na sociedade brasileira, por parte dos setores empresariais, a tentativa de forçar a diminuição do investimento estatal nas entidades públicas, através do estabelecimento de critérios rigorosamente econômicos, como, por exemplo, o retorno que as pesquisas podem dar ao aumento da competitividade industrial.

Na prática, um dos resultados desse movimento é a apropriação, sem nenhum investimento, de todo um know how de pesquisa que as instituições públicas de ensino superior construíram ao longo dos anos. Por outro lado, também se pode observar que as elites industriais, ao estabelecerem critérios mais rigorosos para o financiamento das entidades públicas, estão contribuindo diretamente para essas instituições buscarem outras formas de captação de recursos. Abre-se também, no ensino superior, a possibilidade forçada do autofinanciamento por parte dos estudantes; desejo perseguido pelo Banco Mundial e pelo Banco Interamericano de Desenvolvimento, co-autores das reformas educacionais implementadas na educação brasileira na última década do século passado (Oliveira, 2001b).

\section{Considerações finais}

A preocupação do empresariado industrial com a educação não é algo recente. Desde a criação da CNI, em 1938, esta instituição inseriu a educação na sua agenda, subordinando-a à consecução de seus objetivos econômicos e políticos (Rodrigues, 1998).

Um dos pontos que denotam a diferença da importância atribuída à educação no novo projeto civilizatório desencadeado pelas elites industriais é que a ela não se atribui simplesmente o papel de formação de mão-de-obra para atender aos interesses industriais. Esse objetivo continua presente, mas para o empresariado essa mão-de-obra atualmente deve apresentar níveis de qualificação coetâneos às transformações sociais e econômicas vivenciadas em nível global. O novo trabalhador

\footnotetext{
[...] precisaria combinar velhas e novas habilidades, isto é, as características do padrão fordista de organização do processo de trabalho industrial e as da emergente especialização flexível: habilidades manipulativas para operar a maquinaria; e, simultaneamente, capacidade de abstração, a fim de prever os erros do complexo produtivo integrado e automatizado, cuja vulnerabilidade tecnológica é consideravelmente maior do que aquela presente na linha de produção fordista. (Rodrigues, 1998, p. 138).
}

Nos documentos analisados, o empresariado nacional, de diversas formas, busca demonstrar ao go- 
verno e à sociedade a necessidade de o sistema educacional sofrer alterações de forma a se tornar articulado aos interesses industriais. Fundamentalmente, esses interesses dizem respeito à constituição de uma economia competitiva e capaz de disputar o controle do mercado nacional e fatias do mercado mundial. Entretanto, a concepção de uma economia competitiva formulada por esse empresariado precisa ser questionada à luz do projeto global que as elites estão instituindo, não só no interior da sociedade brasileira, mas pela maioria dos dirigentes nacionais em toda a América Latina.

A articulação entre educação e competitividade industrial que o empresariado defende assenta-se na compreensão de haver, no contexto atual, uma igualdade de oportunidades para as economias nacionais. Sabe-se que essa igualdade é mera retórica. Além de existirem diversos fatores econômicos, sociais e políticos que colocam as economias em desenvolvimento e as industrializadas em pólos distintos da competição econômica, não se pode esquecer a dependência e a subordinação em que as nações em desenvolvimento vivem, em relação ao grande capital financeiro internacional. Não se pode ignorar essa dependência como um elemento fundamental de impedimento para que essas economias possam estabelecer estratégias autônomas de desenvolvimento, principalmente no que concerne a maiores investimentos na área de ciência e tecnologia.

Os neoliberais escamoteiam que a competitividade industrial é definida com base em uma totalidade, e não apenas na qualificação da mão-de-obra. Ora, sabe-se que o capital, em seu processo de internacionalização, tem buscado áreas que lhe assegurem maior liberdade de reprodução, tanto no que se refere aos aspectos ligados diretamente à produção, como é o caso da qualificação dos trabalhadores, como também aos que têm uma relação direta com o conflito capital e trabalho, tais como a presença de uma organização forte dos trabalhadores ou o conjunto de regulações trabalhistas existentes em determinada nação. Essas questões interferem diretamente na possibilidade de contratação de novos trabalhadores no contexto atual.
Ou seja, há mais fatores que definem a possibilidade de inserção no mercado de trabalho que apenas a apresentação de um conjunto de competências que interessam ao capital.

Da mesma forma que para os trabalhadores há um elenco bem maior de fatores que dizem respeito às facilidades ou dificuldades para inserir-se no mercado de trabalho, no campo da competitividade entre nações não é diferente. Os apologistas do capital e da competitividade evidentemente não revelam que os papéis exercidos pelos países subdesenvolvidos na divisão internacional do trabalho são fundamentalmente secundários e referem-se à produção de mercadorias com menor valor agregado. Em outras palavras, as economias periféricas apresentam desvantagem econômica, não em virtude da menor qualificação de seus trabalhadores, como propagam os defensores da teoria do capital humano e da competitividade industrial, mas têm um papel subordinado em virtude de relações de dominação e de dependência política e econômica, as quais só podem ser entendidas compreendendo-se as novas estruturais globais presentes na nova fase do capitalismo globalizado.

Não se pode aceitar o discurso das elites empresariais e das instituições ligadas ao capital, afirmando que a globalização da economia tem como corolário a ampliação de oportunidades de soerguimento das economias periféricas. Na verdade, há maiores possibilidades de tais economias sucumbirem, em virtude das relações de dependência que as mesmas têm com o sistema financeiro internacional, como demonstram os índices de pobreza cada vez mais exacerbados. Conforme Chossudovsky (1999), a globalização tem sido muito mais responsável por universalizar a pobreza que por permitir o aumento da participação dos países periféricos na partilha da riqueza produzida.

Outro ponto que merece ser destacado das afirmações feitas pelo empresariado industrial brasileiro refere-se à modalidade de educação reservada para os setores populares. O empresariado advoga que o Estado deve assegurar para os setores populares educação profissional capaz de propiciar-lhes maiores oportunidades de inserção no mercado de trabalho. Esse é o exato 
limite da visão reducionista dessas elites; não vislumbram para a classe trabalhadora o acesso a níveis mais elevados na hierarquia do sistema educacional.

Para os representantes do capital, o máximo que deve ser garantido para os mais pobres é o acesso ao ensino fundamental, no qual seriam disponibilizados, a partir de uma mudança de sua qualidade, os conhecimentos básicos que assegurariam aos trabalhadores a aprendizagem de novos conhecimentos requisitados pelo mundo do trabalho. Ou seja, para a elite, aos filhos dos trabalhadores deve ser reservado apenas o conhecimento necessário para agregar valor à sua força de trabalho.

Como foi tentado comprovar, por parte do empresariado há não só a preocupação de articular a educação com o processo de desenvolvimento econômico, mas, fundamentalmente, a de garantir mudanças na política educacional de forma que a mesma se torne coetânea das modificações estruturais que o empresariado cobra do poder público. Em outras palavras, na análise das propostas empresariais para a educação, devem ser consideradas tanto a sua postura de buscar a subserviência do processo educativo aos interesses imediatamente econômicos, como também de criar nova institucionalidade para a educação pública no âmbito de uma estrutura político-econômica de cunho neoliberal.

RAMON DE OLIVEIRA, doutor em educação pela Universidade Federal Fluminense, é professor adjunto do Centro de Educação da UFPE. Publicações recentes: A teoria do capital humano e a educação profissional brasileira (Boletim Técnico do SENAC, v. 27, n 1, 2001); A divisão de tarefas na educação profissional brasileira (Cadernos de Pesquisa, $\mathrm{n}^{\circ} 112,2001$ ); O Banco Mundial e a educação profissional (Boletim Técnico do SENAC, v. $\left.27, n^{\circ} 2,2001\right)$ e Elementos para a análise das reformas do ensino médio e da educação profissional no Brasil (Contexto e Educação, no 64, 2002).E-mail: ramono@elogica.com.br

\section{Referências bibliográficas}

BORON, A., (1995). A sociedade civil depois do dilúvio neoliberal. In: SADER, E., GENTILI, P. (orgs.). Pós-neoliberalismo: as políticas sociais e o Estado democrático. São Paulo: Paz e Terra.
(1999). Os "novos Leviatãs” e a pólis democrática: neoliberalismo, decomposição estatal e decadência da democracia na América Latina. In: SADER, E., GENTILI, P. (orgs.). Pós-neoliberalismo II: que Estado para que democracia? Petrópolis: Vozes.

CHOSSUDOVSKY, Michel, (1999). A globalização da pobreza: impactos das reformas do FMI e do Banco Mundial. São Paulo: Moderna.

CONFEDERAÇÃO NACIONAL DA INDÚSTRIA (CNI), (1988).

Competitividade industrial: uma estratégia para o Brasil. Rio de Janeiro: CNI.

, (1993). Educação básica e formação profissional: a visão dos empresários. Texto apresentado na VI Reunião de Presidentes de Organizações Empresariais Ibero-americanas realizada em Salvador, BA, de 12 a 16 de julho de 1993. Rio de Janeiro: Senai/Departamento Nacional.

, (1998). Competitividade e crescimento: a agenda da indústria. Brasília: CNI.

FEDERAÇÃO DAS INDÚSTRIAS DO ESTADO DE SÃO PAULO (FIESP), (1995). Livre para crescer: proposta para um Brasil moderno. $5^{\mathrm{a}}$ ed. São Paulo: Cultura.

FERREIRA, Carlos E. Moreira, (1995). Entrevista concedida a Nair Keiko Suzuki e Alexandre Gambirasio. Noticiais, [s.n.], 14 ago., p. 4-13.

FRIGOTTO, Gaudêncio, (1989). A produtividade da escola improdutiva: um (re)exame das relações entre educação e estrutura econômica social e capitalista. São Paulo: Cortez.

, (1995). Os delírios da razão: crise do capital e metamorfose conceitual no campo educacional. In: GENTILI, Pablo. (org.). Pedagogia da exclusão: crítica ao neoliberalismo em educação. Petrópolis: Vozes. p. 77-108.

GENTILI, Pablo, (1994). O discurso da "qualidade" como nova retórica conservadora no campo educacional. In: GENTILI, P., SILVA, T.T. (orgs.). Neoliberalismo, qualidade total e educação: visões críticas. Petrópolis: Vozes. p. 111-177.

, (1995). Adeus à escola pública: a desordem neoliberal, a violência do mercado e o destino da educação das maiorias. In: GENTILI, Pablo (org.). Pedagogia da exclusão: crítica ao neoliberalismo em educação. Petrópolis: Vozes. 
(1998). A falsificação do consenso: simulacro e imposição na reforma educacional do neoliberalismo. Petrópolis: Vozes.

INSTITUTO HERBERT LEVY (IHL), (1992). Educação fundamental \& competitividade empresarial: uma proposta para a ação do governo. São Paulo: IHL.

INSTITUTO NACIONAL DE ESTUDOS E PESQUISAS (INEP), (1999). Educação para o século XXI: o desafio da qualidade e da eqüidade. Brasília: MEC/INEP.

OLIVEIRA, Ramon de, (2001a). A teoria do capital humano e a educação profissional brasileira. Boletim Técnico do SENAC, v. $27, \mathrm{n}^{\mathrm{o}} 1$, p. $27-37$. , (2001b). Políticas do ensino médio e da educação profissional no Brasil - anos 90: subordinação e retrocesso educacional. Tese de Doutorado. Programa de Pós-Graduação em Educação da Universidade Federal Fluminense.

PORTELLA FILHO, Petrônio, (1994). O ajustamento na América Latina: crítica ao modelo de Washington. Lua Nova, $\mathrm{n}^{\circ} 32$, p. 101-132.
RODRIGUES, José dos Santos, (1998). O moderno príncipe industrial: o pensamento pedagógico da Confederação Nacional da Indústria. Campinas: Autores Associados.

SALAMA, Pierre, (1995). Para uma nova compreensão da crise. In: SADER, E., GENTILI, P. (orgs.). Pós-neoliberalismo: as políticas sociais e o Estado democrático. São Paulo: Paz e Terra.

SILVA, Tomas Tadeu, (1994). A "nova" direita e as transformações na pedagogia da política e na política da pedagogia. In: GENTILI, P., SILVA, T.T. (orgs.). Neoliberalismo, qualidade total e educação: visões críticas. Petrópolis: Vozes.

TOMMASI, Lívia, WARDE, Mirian J., HADDAD, Sérgio (orgs.), (1996). Banco Mundial e as políticas educacionais. São Paulo: Cortez/PUC-SP/Ação Educativa.

Recebido em abril de 2002 Aprovado em outubro de 2002 